\title{
Economia de apropriação e redistribuição de imagens na prática artística de Anna Bella Geiger nos anos 1970
}

\author{
Fernanda Albertoni* \\ University of the Arts London \\ Universidade Federal do Rio Grande do Sul
}

\begin{abstract}
Resumo
Com a mudança de sua prática de arte da gravura para incorporações de novas mídias nos anos 1970, a obra de Anna Bella Geiger não só refletiu uma afinidade com a tecnologia de seu tempo, como também, através da apropriação de imagens fotográficas, estabeleceu relações intemporais, isto é, fora do tempo cronológico, com o que a artista compreendia como elementos formativos da cultura do presente. Assim sendo, examinaremos como duas obras dessa fase da obra de Geiger, Circumambulatio (1972) e Polaridades (1970-74), podem contribuir para uma compreensão crítica do papel da circulação de imagens na formação de memória e da cultura de um tempo.
\end{abstract}

\section{Palavras-chave}

Anna Bella Geiger; imagem; fotografia; memória, arquivo.

Appropriation and redistribution economy in the 1970s art practices of Anna Bella Geiger.

\section{Abstract}

During the 1970s the art practice of Anna Bella Geiger shifted from printmaking to the incorporation of new media. This change reflected not just her affinity with the technology of the time, but, through the appropriation of photographic images, also established atemporal relations with what the artist considered formative elements of the current culture. In this context this article examines how two of Geiger's works from this period, Circumambulatio (1972) and Polaridades (1970-74), can contribute for a critical understanding of the role of circulation of images in the formation of memory and culture of a time.

\section{Key-words}

Anna Bella Geiger; image; photography; memory, archive.

\footnotetext{
* Fernanda Albertoni é doutoranda em projeto colaborativo entre TrAIN (Research Centre for Transnational Art, Identity and Nation), na University of the Arts London, e Universidade Federal do Rio Grande do Sul. Sua pesquisa, intitulada Reordenando imagens e construindo memória: três artistas-arquivistas no Brasil, teve apoio da CAPES. Com especialidade em teoria, história e crítica de arte, tem especial interesse em estudos da memória, práticas do arquivo e escritos de artista na arte contemporânea. Fernanda foi uma das organizadoras do grupo de pesquisa Studying Latin American Art Group (vinculado ao TrAIN) e publicou sobre arte contemporânea em revistas especializadas em arte e publicações acadêmicas no Brasil e no Reino Unido.
} 
A obra de Anna Bella Geiger (Rio de Janeiro, 1933), em sua pluralidade que passa por diversas linguagens e suportes - começando pela gravura e passando pela pintura, produção e apropriação de objetos e imagens, fotografia, e vídeo -, conecta-se entre si através de certos temas recorrentes - como analisado pelos críticos de arte Fernando Cocchiarale (apud Geiger, 1996: 9), Adolfo Montejo Navas (2007: 16) e Dária Jaremtchuk (2007: 85-86). No fim dos anos 1960, Geiger passa por uma das mudanças de linguagem mais significativas em sua trajetória - da gravura para a experimentação com novas mídias -, e a prática investigativa sobre ligações entre imagens arcaicas e sua recorrência no presente emerge como um dos eixos de seus trabalhos. Para essa operação, a artista faz uso da nova tecnologia ligada à imagem de massa e sua reprodução, que se sedimenta na época. Assim, pode-se dizer que Geiger começa a construir um corpo de trabalho que, como observado por Walter Benjamin, não negligencia "as correspondências entre o mundo da tecnologia moderna e o mundo arcaico dos símbolos da mitologia” (2006: [N 2a, 1] 503).
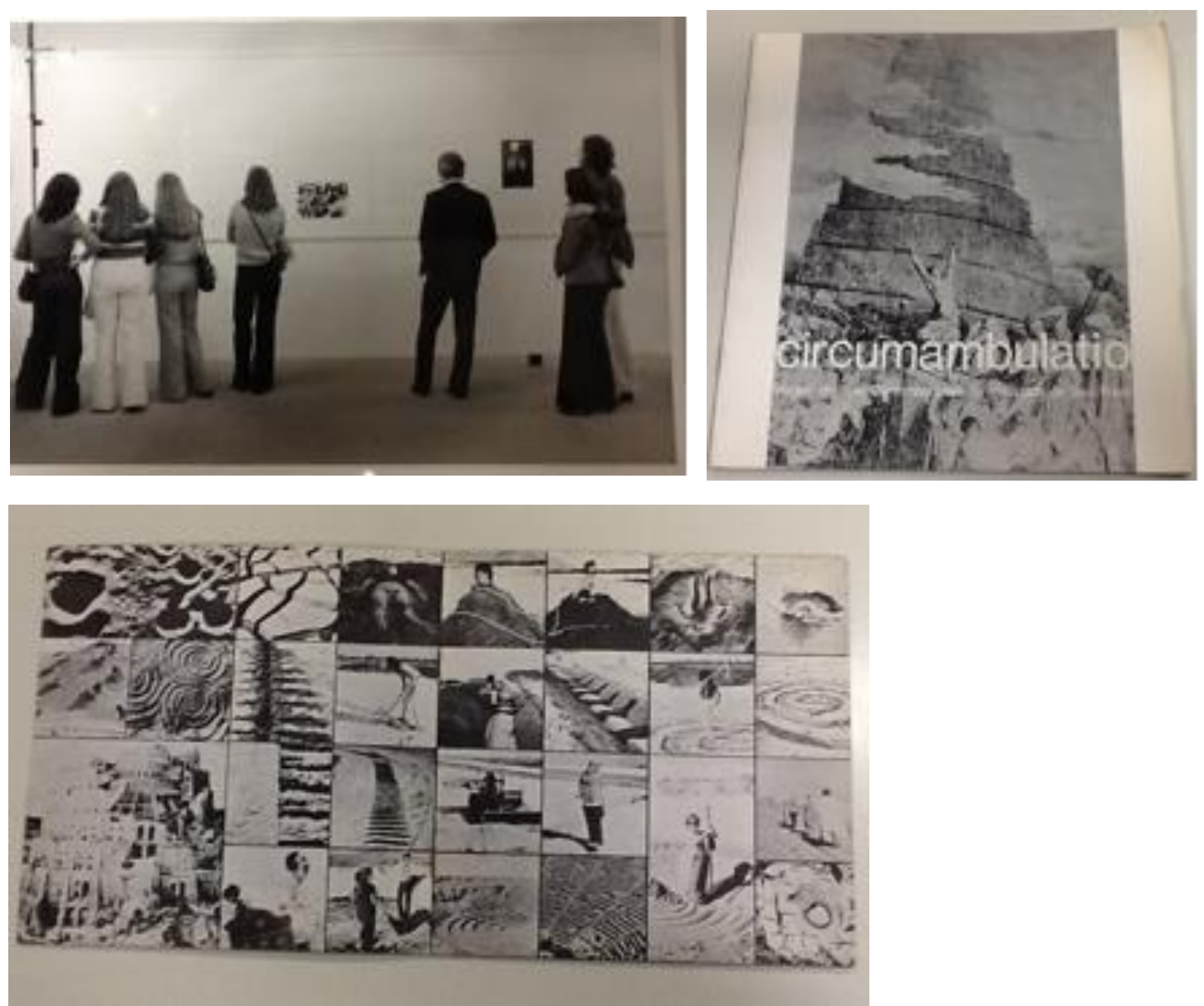

Fig. 1. Circumambulatio, 1972 (em sentido horário de cima: vista da exposição no MAC USP, 1973, e capa dp folder-catálogo da exposição em montagem no MAC USP, vista interna das imagens no catálogo). Fonte: Arquivo MAC USP. 
Como eixo dessa pesquisa tem-se a inquisição de Geiger sobre formas circulares que aparecem como simbolismos centrais em diversos tempos e culturas. Tal investigação teve como marco inicial o trabalho coletivo Circumambulatio (1972), um evento-instalação com registro de ações e reproduções de imagens que Geiger desenvolveu com os alunos do curso "Arte-Crítica", realizado no Museu de Arte Moderna do Rio de Janeiro em 1972, em que propôs repensar junto com os estudantes o que era arte naquele momento ${ }^{1}$ (2014) [fig.1]. Conforme destacado em uma reportagem sobre 0 curso publicada no Jornal do Brasil na época, o foco das aulas era "trazer o inconsciente do aluno através de símbolos (na sua obra) para o exterior" (apud Jaremtchuk. 2007: 79).

A experiência do curso de arte experimental e 0 consequente desenvolvimento do trabalho Circumambulatio surgem em um período em que a artista relata não conseguir mais "acreditar no sentido de qualquer objeto de arte" (Geiger apud Navas, 2007: 84). Pode-se analisar que esse questionamento conecta-se a um desenvolvimento em de sua linguagem artística - já que na fase anterior, das gravuras Viscerais, a linguagem da própria gravura começa a ser desconstruída pela inserção de outras técnicas na produção de imagens - , e também devido ao processo de mudança da sociedade em que a artista estava vivendo, quando a opressão e a perseguição política começavam a restringir a liberdade individual e segurança de sua família e de outros ${ }^{2}$. No fim dos anos 1960, com seu questionamento sobre a linguagem da arte, aliado à crise política e democrática no país, a artista diz ter se sentido paralisada durante dois anos (a partir de 1969) e interrompe sua produção artística individual (Geiger, 2014). Ela relata, contudo, que continuava a acreditar "no pensamento, na indagação sobre a arte", que ela levava adiante nas aulas que ministrava no MAM-RJ (Geiger apud Navas, 2007: 84). Refletindo em retrospecto sobre esse período de mudança Geiger declara:

É quando começo a enveredar por um caminho mais antropológico. Era como se eu tivesse saindo, me afastando de uma compreensão histórica, me

${ }^{1}$ Geiger começa a ensinar no MAM-RJ em 1968, onde desenvolve cursos até 1973. No período foram realizados no museu uma série de cursos de arte-educação coordenados por artistas voltados ao desenvolvimento da criatividade e experimentação. Como analisa a historiadora da arte Dária Jaremtchuk, "os cursos distinguiam-se pela experimentação que realmente ultrapassava o mero ensino de técnicas e de exploração de suportes tradicionais" (2007: 78).

2 Em 1964 o marido de Anna Bella Geiger, o geógrafo Pedro Geiger, foi preso, acusado de comunismo. Envolvido com uma linha progressiva da nova geografia nos anos 1960, ele estudava e propunha uma divisão do território brasileiro não só baseada em características naturais, mas levando-se em conta relações entre industrialização, migração, desenvolvimento socio-econômico, que ele acreditava afetar a configuração de territórios - o caso, por exemplo, que se reflete em seus estudos nos anos 1950, da cidade do Rio de Janeiro e baixada fluminense (Alves, Pinto, 2012). Durante o governo de Carlos Lacerda no Estado da Guanabara (1960-65), Pedro Geiger foi convidado a participar da criação do Instituto de Geografia do Rio de Janeiro. Contudo, devido a visões políticas divergentes com o governo estadual, Pedro foi acusado de atos comunistas e temporariamente preso (Geiger, 2014). Portanto, mesmo antes da radicalização do AI-5 em 1968, a crescente onda de repressão política no país já afetara diretamente a família de Geiger. A artista declara que esse episódio, em que viu o marido ser levado de casa sem saber para onde, marcou não somente sua história familiar, como também começou a afetar sua visão sobre a o papel e função da arte naquela sociedade: "levaram o Pedro assim, na marra. [...] Eles levavam, não se sabia para onde [...]. Essas coisas vão tecendo a gente também...", declara a artista (Geiger, 2014). 
distanciando dela para poder aceitá-la. Dentro de um outro espaço, do mito, sei lá, eu parecia entender melhor como alavancar questões. (Geiger apud Navas, 2007: 84).

Conforme suas declarações, ela estava quebrando com um "entendimento histórico" da sociedade para poder processar o que estava acontecendo ao seu redor. Recusando a noção de um desenvolvimento linear e progressivo do tempo e o paradigma da compreensão do presente dentro de uma revisão histórica, pode-se analisar que Geiger estava em busca de outras fontes ou modelos para entender elementos daquela sociedade - modelos esses que não respondiam a sequências cronológicas, mas que propunham outros caminhos de conexão entre a realidade e suas estruturas simbólicas e materiais. Como propõe Benjamin, e sendo relevante para lógica de Geiger, "a essência do acontecimento mítico é o retorno", que é secretamente inscrito em figuras e eventos, que são por sua vez relacionados através de um "eterno retorno" (2006: [D 10a,4] 159). No lugar de uma progressão lógica da história, Geiger escolhe uma "direção antropológica" - como indica a artista - como metodologia e estratégia para a busca de novas conexões da arte com formas e contextos do seu entorno, ocasionando, assim, um redirecionamento de seu trabalho para uma prática artística mais contextual e com extensões em outras disciplinas e áreas.

Em relação aos primeiros passos de expansão de sua prática em direção a outros campos, Geiger afirma que desde os anos 1960 ela "já vinha adentrando certas questões na arte, dentro do simbólico, dentro do inconsciente coletivo, pensamentos não só do [Carl] Jung, mas de historiadores com quem eu tinha entrado numa leitura, em que me interessava muito mais o significado do artista como um anônimo" (2014). Nesse contexto, um dos principais autores que reflete 0 interesse de Geiger no compartilhamento de uma experiência simbólica através da arte é o historiador da religião Mircea Eliade (Geiger apud Navas, 2007: 87). Pesquisando mitologia e história da cultura em diferentes sociedades, o pensamento de Eliade - assim como o de outros autores de sua geração que se aproximavam de um viés antropológico ${ }^{3}$ - questionava a supremacia do conhecimento racional do Ocidente. Segundo Eliade, mitos atravessam diferentes tempos e sociedades em ciclos de retorno, e podem ser encarados como um "modo autônomo de conhecimento" (1991: 5). Através de seu registro em hierofanias - a aparência ou manifestação do sagrado na cultura humana -, mitos e símbolos não só apresentam modelos ideais que dão valores, direções e propósitos para o trivial do mundo humano, mas também, consequentemente, fundam um modelo do mundo. Assim, conforme o pensamento de Eliade, símbolos e rituais não somente comemorariam o sagrado, mas o criariam, e a

\footnotetext{
${ }^{3}$ Podemos citar como outros modelos alternativos à racionalidade ocidental a emergir na época os arquétipos de Carl Jung, mitos de Georges Bataille (com quem Eliade colaborou na publicação Critique, em 1948), e o estruturalismo de Claude Lévi-Strauss. 
realidade seria modelada por representações de modelos criados por mitos (1991).
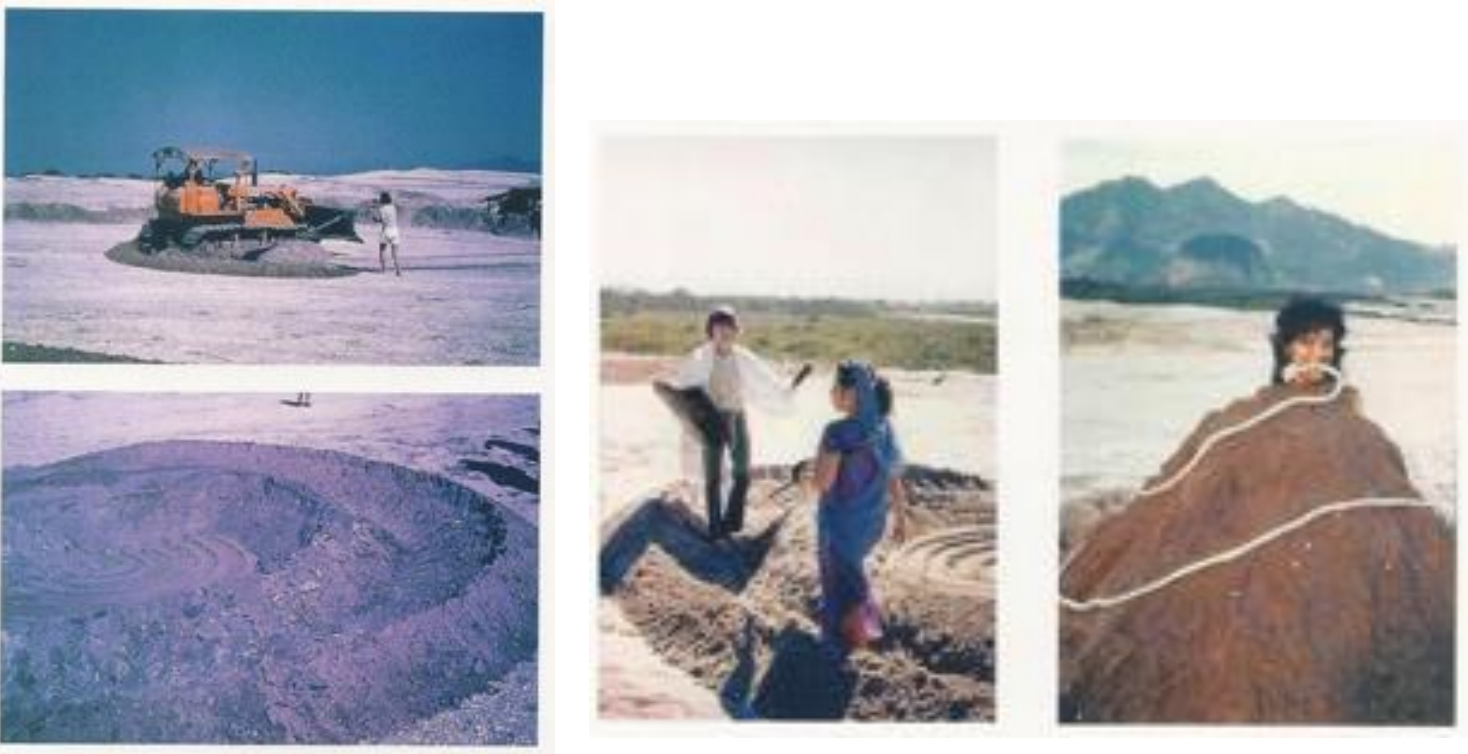

Fig.2. Circumambulatio, 1972 (diapositivos). Fonte: Jaremtchuk, 2007: 158-159.

Em compartilhado interesse com os alunos do curso experimental no MAM/RJ, e sob a influência do pensamento de Eliade, Geiger e o grupo desenvolveram uma investigação sobre a sobrevivência e lugar do simbólico e do mitológico relacionados a imagens e formas circulares na cultura contemporânea. Seguindo estratégias de trabalho de campo de viés antropológico na busca de espaço e imagens que remetessem ao eixo central da investigação, eles começam a visitar áreas da Barra da Tijuca que na época eram desertas. Lá, investigando a recorrência e o significado de círculos e centros como "formas elementares" em seu tempo e sociedade, o grupo realizou uma série de ações como exercícios de inscrições dessas formas no solo - ações essas que foram registradas em fotografia e super-8 (fig. 2).

Alinhados ao pensamento do Eliade, eles investigavam o limite tênue no qual os significados dessas formas - tais como o círculo como o símbolo da terra, ou como uma noção de totalidade e centralidade - podem ser conectados à História e a um desenvolvimento histórico, ao mesmo tempo em que transitam por relações intemporais. Além de explorar as possibilidades práticas de reinterpretar essas formas, o grupo também coletou imagens fotográficas de jornais, revistas, catálogos e outras publicações (científicas, históricas, antropológicas, e de arte) que remetessem à recorrência do círculo, e fez uma seleção de trechos de obras que se referiam a centros - a maioria extratos de 
outros autores ligados a estudos da cultura humana, história e psicologia, mas também textos de autores literários e artistas 4 .

Em seguida, a documentação das ações, reproduções de imagens, citações bibliográficas e trechos redigidos pelo próprio grupo foram inseridos em painéis distribuídos de forma labiríntica e circular, formando, junto com uma trilha sonora, a exposição-instalação Circumambulatio, realizada no MAM-RJ em 19725. Interconectando todos esses elementos estava a ideia de centro, que como descrito no parágrafo de abertura de Circumambulatio, era vista pela grupo como uma "imagem exemplar":

As imagens exemplares sobrevivem ainda na linguagem e nos clichês do homem moderno. Qualquer coisa da concepção tradicional do mundo se prolonga ainda no seu comportamento, embora ele não esteja sempre consciente dessa herança imemorial. (Circumambulatio, 1972, arquivo MACl USP).

Este trabalho representou uma virada na produção artística de Geiger ou, como analisa Jaremtchuk, "um ponto de inflexão" na trajetória da artista (2007: 81). Isto é, ele marca um momento de transição no conceito, suportes, propósito e definição de seu entendimento da arte, resultando em uma prática mais experimental e multi-midiática a partir de então, mas principalmente no decorrer da década de 1970. Com essa transição, sua prática começa a se conectar à sociedade em seu entorno não só conceitualmente, mas também por meio da apropriação física de elementos da cultura diária. E como elemento recorrente de apropriação estão as imagens de massa.

Se em Circumambulatio a apropriação de imagens desconexas aparece como uma tentativa de compreender a sociedade como uma confluência de um desenvolvimento histórico e da recorrência de mitos e formas, em trabalhos posteriores, dos anos 1970, essa estratégia de apropriação de imagens também problematiza a linearidade e racionalidade de uma compreensão histórica do presente e leva adiante uma proposição poética e crítica quanto à circulação de imagens no tempo presente. Como indicado pela declaração de Geiger sobre sua procura por um entendimento da sociedade através de um modelo outro que o histórico (apud Navas, 2007: 84), as questões refletidas nessa transição também podem ser analisadas como ligadas a mudanças paradigmáticas ocorridas na metade do século XX: com o crescente predomínio do valor das imagens e da informação, que passaram a transitar

${ }^{4}$ Como Eliade, Jung, Abraham Moles, Platão, Pitágoras, João Cabral de Melo Neto, T. S. Eliot, Steinbeck, Fernando Pessoa, Klee, Malevitch, entre outros.

${ }^{5} \mathrm{~A}$ exposicão-instalacão viajou para o MAC/USP em 1973 e foi adquirida pelo museu, sendo hoje parte de seu acervo. No convite e folder da exposição, na versão montada no MAC/USP em 1973, os participantes são creditados como: "Organização: Anna Bella Geiger. Equipe: Abelardo Jacobina, Eduardo A. Escobar, Lígia T. Ribeiro, Suzana Geyerhahn. Colaboração: Frederico Morais, Tomy Lewinsohn e alunos do setor de integração cultural do Museu de Arte Moderna do Rio de Janeiro ( $1^{\circ}$ semestre 1972). Música: Can Tago Mago, Mussorgsky, Emerson Lake e Palmer". 
mais rapidamente e com mais alcance através de canais midiáticos, as ordens da sociedade e a forma como suas narrativas são construídas também se alteraram. A esse respeito, pensadores como da mídia e da cultura, como Vilém Flusser, defendem que a nossa sociedade passou de industrial e histórica - onde narrativas eram predominantemente lineares e progressivas para uma sociedade da informação e midiática - na qual a fragmentação e a sobreposição de referências começam a romper com a linearidade das narrativas (2002). Nesse contexto, as noções de memória coletiva e inscrição do presente enquanto progressões lineares e cronológicas são igualmente abaladas e a relação da arte com o "seu tempo" se torna ainda mais complexa.

Assim, pensando nessas questões em relação ao contexto dos anos 1970 e a nova fase da produção artística de Geiger, pode-se analisar que ambos os aspectos, de recorrência de formas e de confluência de diferentes tempos, estavam se tornando ainda mais relevantes à luz da crescente velocidade de circulação das imagens com o avanço da cultura midiática e de massa. Em função dessa expansiva distribuição de imagens, diferentes tempos e lugares também começaram a se tornar crescentemente interconectados. Logo, o impulso de Geiger em investigar a reemergência de certas formas e imagens em Circumambulatio provou ser um importante passo em direção a um exame crítico das conexões entre imagens e outros elementos culturais que resultam na formação da sociedade e de sua memória - operação essa que se tornaria traço recorrente em sua obra a partir de então. Como Walter Benjamin observou, "todo presente é determinado por aquelas imagens que lhe são sincrônicas: cada agora é o agora de uma determinada cognoscibilidade" (2006: [N 3, 1] 504). Assim, nessa lógica, símbolos e mitologias do passado, quando sincronizados com um atual "agora", podem ser encarados como imagens que criam um reconhecimento para as conexões entre passado e presente, informando sobre a formação do último.

Com uma maior distribuição e circulação de imagens e de informação, referências de outros tempos e culturas se tornam cada vez mais interconectados no presente como um fluxo de memória-imagens, isto é, cenas mentais privadas que são moldadas pela cultura da imagem. Nesse sentido, processos de memória começaram a ser vistos não meramente como formados e preservados no cérebro humano, mas modelados e ativados pelo tecido social que os cerca (Brockmeier, 2002). E um dos principais elementos desse tecido social são as imagens, que não somente estão ao nosso redor, mas também dentro de nós, como imagens-memória. Ao final do século XIX Henri Bergson já observara que imagens-memória não eram parte de um processo de resgate do passado, mas de como a percepção de passado e presente são afetados e construídos através de fluxos de imagens mentais ${ }^{6}$.

${ }^{6} \mathrm{O}$ ponto levantado por Bergson pode ser visto como cada vez mais atualizado pela cultura imagética da segunda metade do século $X X$ 
(1999) Consequentemente, o que se entende por memória consolida-se cada vez mais como um cenário imagético, isto é, formado por reminiscências que não apenas são parte da memória dita "privada", como também são moldadas por uma memória cultural sempre em fluxo. Com a distribuição de elementos da cultura atingindo proporções inéditas no fim do século XX, o especialista em memória Jens Brockmeier dá continuidade à ideia de memória como um cenário imagético, ao afirmar que "memória individual" é "parte inextricável de um discurso cultural de grande alcance", o "discurso da memória cultural" (2002, tradução da autora). Assim, a noção de memória como um arquivo ou armazém de onde partes do passado poderiam ser resgatas começa a ser colocada em xeque, já que, tal como argumenta Brockmeier, elementos da cultura e o próprio processo cognitivo da memória propõem uma reinvenção ou atualização - constante do passado de acordo com estímulos do presente (2015: viii).

Entre Bergson e Brockmeier, a ideia de Vilém Flusser de que as imagens técnicas que se encontram ao nosso redor estão reestruturando a realidade e transformando-a em um "cenário global de imagem"7 (2000: 9, tradução da autora), pode ser vista como uma importante contribuição para a compreensão da conexão entre processos culturais e formações mnemônicas. Afetando 0 que ordinariamente se entende por "realidade", a dinâmica das imagensmemória moldadas pela cultura de massa também participa da constituição do "presente" como uma memória-cenário que cada vez mais inclui referências a outros tempos e culturas. Logo, o presente, como o tempo do agora, torna-se entrelaçado ao passado através da mediação da cultura da imagem de massa.

O uso da expressão "herança imemorial" ao invés de "memorial" no parágrafo de abertura de Circumambulatio indica que o grupo assumia uma mudança na ideia de memória, encarando-a não somente como uma recuperação de forma integral da lembrança, mas também como um processo em fluxo e que incluía o esquecimento. Por "herança imemorial" eles parecem sugerir a transmissão de formas e imagens como um processo contínuo e subliminar em nossa cultura - isto é, não como mensagens codificadas a serem decifradas, mas como elementos que podem emergir de atualizações e reconhecimentos de múltiplas experiências do presente, mas que também podem ser esquecidos ou não reconhecidos. Assim sendo, o uso do conceito de "imemorial" em

\footnotetext{
${ }^{7}$ Como argumentado por Flusser, o caráter aparentemente "objetivo" de imagens técnicas fazem com que elas sejam confundidas com reflexos não simbólicos da realidade. Ou seja, não sendo criticamente decodificadas, elas são olhadas por seus observadores "como se fossem janelas" do mundo (Flusser, 2002: 14). No entanto, Flusser ressalta que "a aparente objetividade das imagens técnicas é ilusória, pois na realidade são tão simbólicas quanto o são todas as imagens" (2002: 14). Indo além, o filósofo analisa que sendo "superfícies que transcodificam processos em cena", as imagens técnicas são, como todas as imagens, "mágicas" e, por isso, "seu observador tende a projetar essa magia sobre o mundo" (2002: 15). Logo, ele conclui que "vivemos, cada vez mais obviamente, em função de tal magia imagética: vivenciamos, conhecemos, valorizamos e agimos cada vez mais em função de tais imagens" (2002: 15-16). Assim, segundo essa lógica, a imagem técnica conecta-se ao mito arcaico através de uma mágica similar a este, re-atualizada no que Flusser chama de seu "programa" - isto é, o modelo de criação e transmissão do aparelho das imagens técnicas (2002: 16).
} 
Circumambulatio pode ser visto como construindo uma ponte com o que Brockmeier iria mais tarde apontar como o potencial das artes em atualizar 0 conceito de memória como uma experiência processual interconectada a contextos socio-culturais (2002 e 2015).

Conectados à instabilidade da noção de presente como uma localização e tempo específicos - um purismo e especificidade utópicos que se rompeu com a circulação de imagens e informação da mídia de massa - Geiger e os estudantes, em Circumambulatio, usaram, portanto, imagens de diversas fontes que retratavam diversas culturas e épocas e exploraram as possibilidades dessas referências cruzadas de cenários culturais plurais e anacrônicos. Assim, as imagens e citações na instalação indicam que ideias similares sobre "centro" aparecem como "herança imemorial" em representações da Via Láctea, em rituais primitivos, mandalas tibetanas, Stonehenge, em pinturas de Miró, em uma ilustração do século XIX de Gustavo Doré sobre a torre de Babel (A Confusão das Línguas, 1865), em centros urbanos, em um anfiteatro romano, no Maracanã (fig.3), entre outras referências.

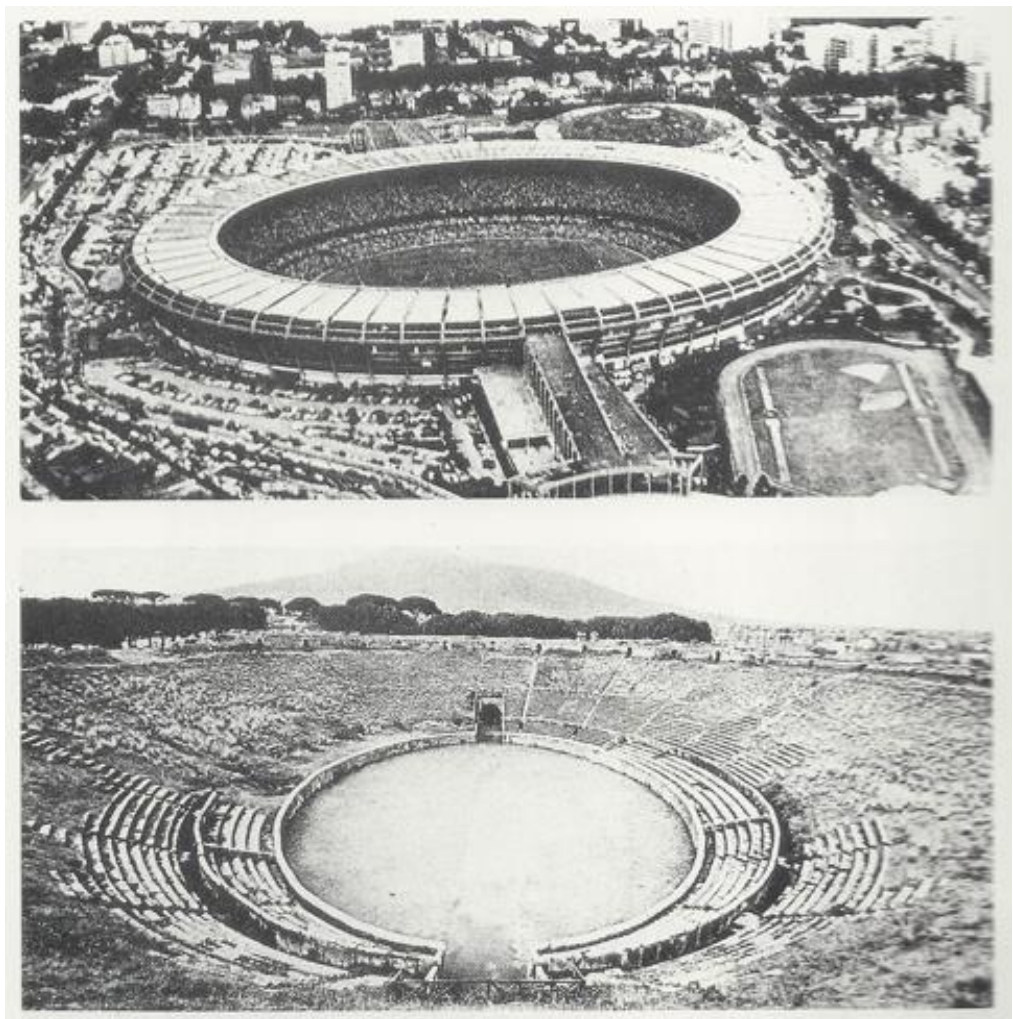

Fig.3.Circumambulatio, 1972 (imagens presentes nos painéis). Fonte: Geiger, 1996: 42

Enquanto o princípio de pesquisa sobre a recorrência de formas e símbolos antigos, tais quais círculos e centros, foi guiado por uma visão que reconhece que forças anacrônicas formam o presente, as ferramentas e meios que Geiger 
incorporou para desenvolver essas pesquisas - tais como fotografia, fotocópia, e vídeo - eram, por sua vez, intrinsecamente conectadas à tecnologia do presente, com uma lógica e funcionamento que se relacionavam de forma seminal à crescente centralidade da circulação de imagens na sociedade de então. Sobre a incorporação não apenas de imagens, mas também de diferentes ferramentas e sistemas na prática e documentação em Circumambulatio, Geiger declara:

Busquei apoio em outros modelos operativos, não como fatores externos ao processo (registros fotográficos, imagens eletrônicas), mas sim como elementos fundamentais para a criação dessa outra realidade, transformada ética e esteticamente. Ou seja, mais que o mero uso dos meios constituintes físicos da obra, me ocupei de um câmbio de outra natureza entre essas mídias tecnológicas que, até então, não eram consideradas instrumento artístico pela crítica especializada. (Geiger, 2012) ${ }^{8}$

Naquele momento de suposta crise e paralisia em relação à sua produção artística, imagens de mídia também desempenharam um papel fundamental na reorientação da prática de Geiger - imagens essas que, mais uma vez, conectavam-se à questão da simbologia de formas circulares em diferentes culturas. Nesse período de dúvidas a artista deparou-se com uma imagem que despertou o desejo de dar continuidade à sua prática artística individual, para além das experiências coletivas que resultaram em Circumambulatio: em 1969 a atenção de Geiger foi capturada pelas primeiras fotografias em close-up colorido da superfície lunar que apareceram na revista Life ${ }^{9}$ (fig.4). O contato com essas imagens tornar-se-ia central na mudança abrupta na obra de Geiger. Refletindo sobre esse episódio em retrospectiva, Geiger declara:

Em 1969 o homem foi a lua. Não me interessou quando começaram as fotos: aquilo do homem no espaço, o umbilical... porque tem um artista que na época põe, que interessante, a criança [referência a imagens de um astronauta conectado à nave espacial através de um cabo]... Mas começam a vir na

\footnotetext{
8Jaremtchuk interpreta essa expansão de ferramentas e meios, bem como a incorporação de traços de outros campos em Circumambulatio como um sinal de aproximação de sua prática com "características conceituais", já que "a função da arte foi ampliada e expandida para investigações extra-artísticas e reflexivas, com o envolvimento de diversos campos do saber humano, como a antropologia cultural, a psicologia e a história" (2007: 85). Levando em consideração o argumento de Jaremtchuk e concordando que a hipótese de aproximação com uma prática conceitual não deve ser descartada, o enfoque desse artigo não é um reposicionamento historiográfico da prática de Geiger em relação a movimentos artísticos canônicos do século XX, mas uma investigação das conexões anacrônicas e fragmentárias da obra de Geiger com narrativas da cultura, história e memória - e, consequentemente, com uma pré-história das práticas arquivísticas que tomariam a arte no fim do século XX - por meio da apropriação e redistribuição de imagens de massa.

${ }^{9} \mathrm{~A}$ revista Life, que nos anos 1960 cobriu extensivamente a corrida espacial, publicou imagens em close-up da superfície lunar em pelo menos quatro capas de suas edições em 1969: a capa da edição de 6 de junho de 1969 trazia uma fotografia tirado do Apollo 10 voando próximo à lua; a da edição de 8 de agosto de 1969 tinha uma imagem da bandeira americana fincada em solo lunar pelo tripulantes da Apollo 11; nessa mesma semana, em 11 de agosto de 1969, foi lançada uma edição especial cobrindo a jornada da nave espacial Apollo 11; e em 12 de dezembro de 1969 a capa trouxe fotos tiradas pela Apollo 12. Em entrevista à autora (Geiger, 2014), Anna Bella Geiger falou sobre a experiência de ter sua atenção capturada pelas "primeiras imagens coloridas da superfície da lua" que foram publicadas na revista Life - mas ela não lembrava exatamente em que edição. É interessante notar que para o público dos anos 1960 essas primeiras fotografias detalhadas, em cores, da superfície lunar eram um representação visual sem precedentes, que davam finalmente conta da dimensão visual reportada por astronautas - mas que o público em geral estava acostumado a ver em preto e branco.
} 
revista Life, na capa, registro em cor, a possibilidade de cor naquelas superfícies lunares, nas crateras. [...]. Aí pronto, encontrei meu mundo de novo. Porque na hora que eu vi as fotos eu não conseguia pensar na foto, eu só dizia 'eu preciso dessa vibração dessa cor dessa superfície dessas crateras'. Não era a lua com todas as craterinhas [que a interessava]... (Geiger, 2014).

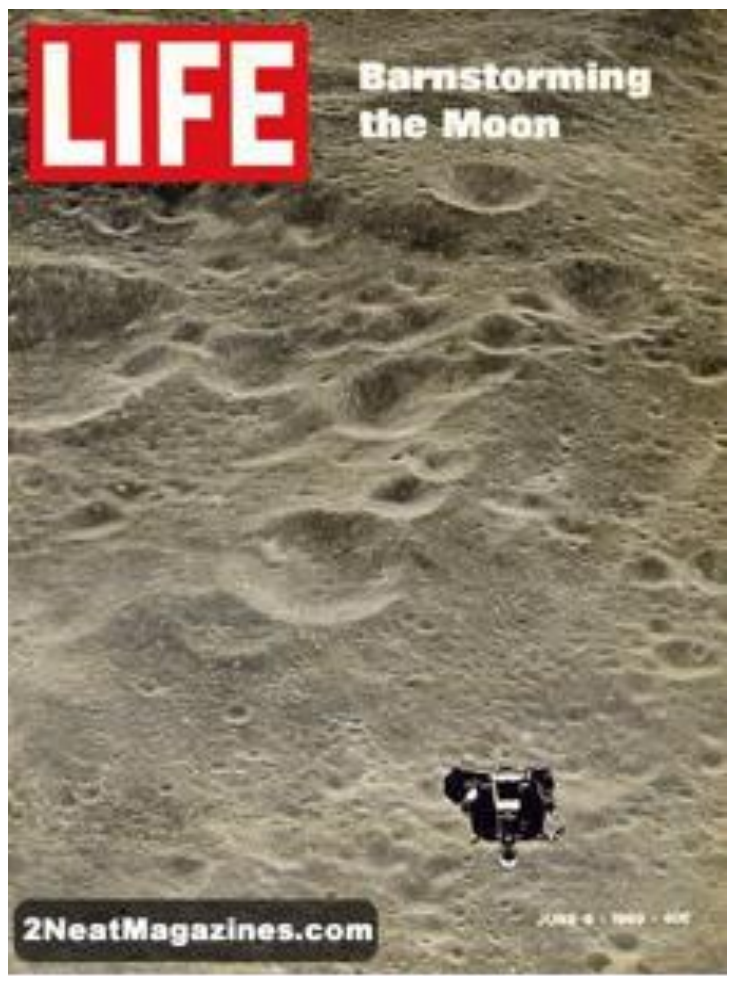

Fig.4. Capa da revista Life, 6 de junho de 1969.

A declaração de Geiger indica como a fotografia, que era parte dessa nova tecnologia de meios de massa, levou-a de volta ao universo gráfico, que era parte da sua fundação artística. Tendo seu interesse despertado por essas imagens em 1969, Geiger demorou alguns anos para que desenvolver a ideia e técnica do trabalho que queria fazer com elas. Esse foi um processo paralelo à experiência de Circumambulatio - enquanto desenvolvia o trabalhoinstalação em grupo, a artista também estava em seu atelier experimentando com imagens que também se relacionavam a uma noção de território (2014). Lidando com o trabalho de campo em Circumambulatio, ela conta que essa experiência despertou-lhe a vontade de trabalhar com imagens que se relacionassem à experiência de uma demarcação simbólica do espaço:

Precisava urgentemente usar algumas fotos, mas que fotos? Imagens de um terreno qualquer. Nesse envolvimento com os cursos eu só pensava naquilo, numa imagem do território o mais neutro possível. Só ali, naqueles fotos, gravadas e impressas, eu poderia declarar alguma coisa, com marcas profundas (Geiger apud Navas, 2007: 86). 
Logo, não era a "representação" da lua que a interessou inicialmente, mas sim como a superfície lunar capturada naquelas fotografias continha certos elementos gráficos próximos da abstração - elementos esses que a interessavam como uma linguagem vibrante que ela queria explorar. De acordo com Geiger, buscando acesso a algumas dessas imagens que vira na revista Life, ela foi ao setor de imprensa do consulado dos Estados Unidos no Rio de Janeiro e pediu cópias das fotografias, conseguindo obter provas fotográficas tais quais as fornecidas pela NASA à revista (Geiger apud Navas, 2007: 86).

Algumas das imagens contidas nas folhas de prova estavam marcadas como "erradas" e cruzadas por cima pela NASA. Geiger conta que "o que me interessava mais eram as fotos consideradas imperfeitas para publicação, cuja transmissão da imagem não tinha nitidez absoluta" (apud Navas, 2007: 86). A artista afirma que "aquilo [0 acesso a essas imagens] foi a minha descoberta do mundo. Porque aí eu disse: 'é aí nesse território que eu tava fazendo com terra que eu vou falar sobre a situação política'" (2014). Ela decidiu então usar as imagens marcadas graficamente com cruzes, que ela traduziu como um dualismo classificatório de "certo" ou "errado", um território metafórico para falar sobre a complexidade da situação política e cultural no Brasil naquela época. Refletindo em retrospecto, ela observa que: "eu dizia, com a polaridade eu não estou dizendo que $a$ ou $b$ estão lutando, mas as duas existem nesse pensamento fragmentado" (2014).

Conectando essas imagens com sua prática gravurista anterior, Geiger, em 1970, experimentou como transferir as imagens fotográficas para placas de metal, e como transformar essas placas em foto-gravura (Geiger apud Navas, 2007: 86). Nesse processo começou a refletir sobre definições, conceitos e limites entre ambos os meios como linguagens visuais ${ }^{10}$. Geiger fez então uma transição e ponte entre a fotografia e a gravura e, sem abandonar a linguagem gráfica da gravura, começou a trabalhar com uma composição visual que partia de um dado "material pré-codificado" como base para a imagem"11. A artista não estava em total controle na criação das imagens - já que a base delas era apropriada de fotografias - nem tampouco estava totalmente transferindo 0 significado simbólico das imagens tais quais apareciam na capa e páginas da revista Life. Tomando como base essas imagens da lua, apropriadas e transferidas para placas de gravura em metal, Geiger criou a série Polaridades,

\footnotetext{
10 Rosalind Krauss observou que, historicamente, o advento da fotografia deu um novo valor para gravuras, provas e outros procedimentos de produção de imagens que eram baseados em "traços", e que eram, até então, considerados secundários e desvalorizados em relação às "principais" produções de arte como pintura e escultura (1986: 216-217) - argumento similar foi desenvolvido por Georges Didi-Huberman (1997).

${ }^{11} \mathrm{O}$ termo "material pré-codificado" (original em inglês, "precoded material") foi usado por Lawrance Alloway na definição da arte Pop americana - importante lembrar, no entanto, que seu interesse pelos cruzamentos entre arte e cultura de massa data de seu envolvimento com o Independent Group no final dos anos 1950. De acordo com o crítico, a prática da arte Pop era essencialmente "sobre signos e sistemas de signos", isto é, uma arte que lida com "materiais que pré-existem como signos: fotografias, marcas, quadrinhos - em outras palavras, com materiais pré-codificados" (Alloway, 1974: 7).
} 
1970-74, dos quais são parte Certo Errado, 1973 (fig.5) e Aqui é o Centro, 1973.

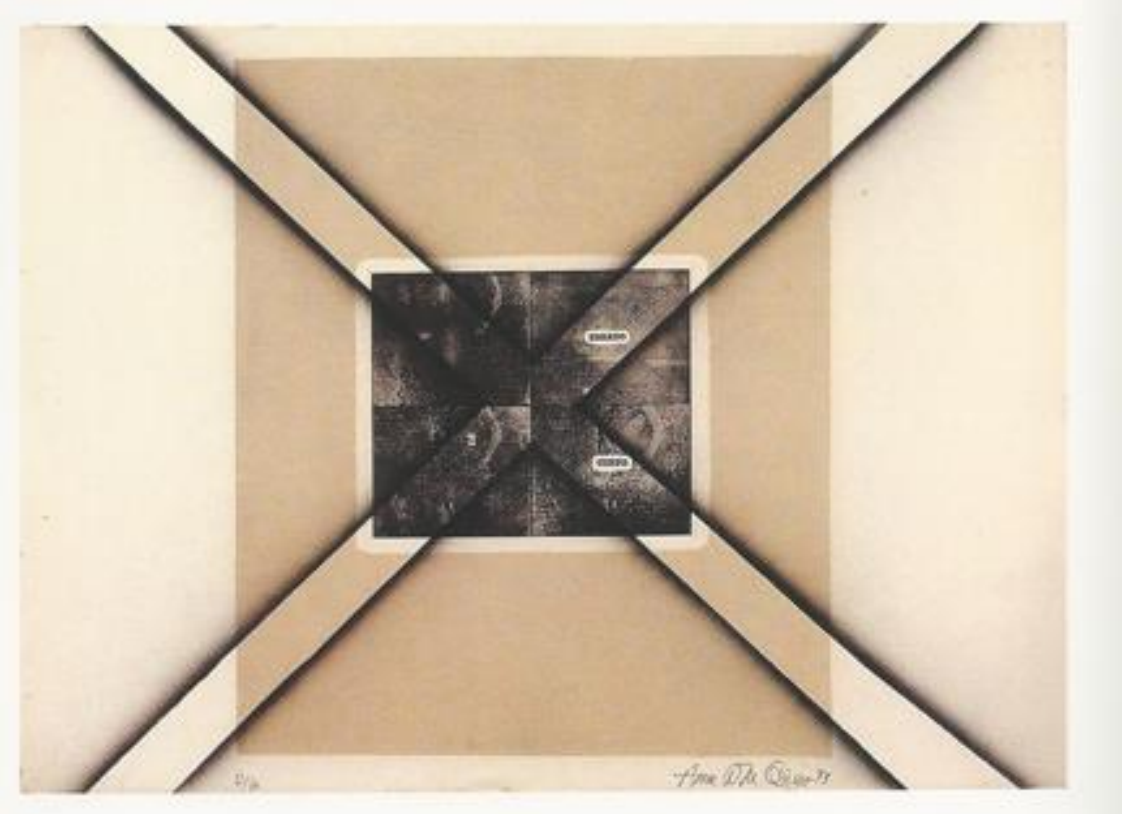

Fig.5. Certo errado, 1973 (serigrafia e fotogravura em metal, 55,5 x $76 \mathrm{~cm}$ ). Fonte: Geiger, 1996: 34.

Como observado por Luiz Cláudio da Costa em relação à tendência, nos anos 1960, em usar tecnologias de reprodução de imagem, essas práticas tendem a evidenciar "figuras e desfigurações idealizadas da cultura", sugerindo um "caráter múltiplo das imagens" (2014: 31; 42). Ele argumenta que "o múltiplo como cópia de uma matriz permite a circulação, mas também a própria experiência da divisão das imagens" (2014: 42). Nesse sentido, ao usar a superfície da lua como base para diferentes composições, Geiger jogou com essa divisão de imagens e seus significados através de noções opostas ou dualistas como certo e errado, centro e periferia, parte e todo. Inscrevendo essas palavras em certas partes das fotogravuras, ela criou mapeamentos ideológicos e dualistas de territórios de forma ao mesmo tempo abstrata porque ressalta a tendência a um grafismo abstrato da imagem - e figurativa - já que usava como base um território específico de alto valor simbólico. Através dessas divisões e fragmentações da imagem e o estabelecimento de conexões com outras linguagens, mesmo que a superfície da lua ainda seja facilmente identificável, os significados são mais ambíguos. Em vez de ser uma ilustração sobre um território disputado geopoliticamente - o que a lua, naquela época, de fato era -, tais imagens parecem estar se referindo a uma mais complexa confluência de fatores culturais, políticos, geográficos e econômicos. 
Na opinião de Glória Ferreira, as práticas de arte nos anos 1970 no Brasil foram "marcadas pela disparidade de temas, técnicas e matérias", e os significados e fundação em que essa produção se desenvolvia eram visíveis "na própria externalidade da linguagem" (2009: 23). No caso de Geiger, lidar com essa "externalidade da linguagem", com a apropriação de certos elementos da mídia de massa, assim como com os "materiais pré-codificados" que circulavam por esses canais, não significou uma estrita reflexão sobre a ascendência da cultura de massa na corrente sociedade. Pode-se dizer que Geiger usou a exterioridade ou superfície de linguagens e meios para estabelecer conexões entre assuntos de diferentes universos. Assim, em seus trabalhos, significados não se restringem a uma imersão vertical em um assunto ou meio, mas são construídos através de pontos de contato que ela estabelece entre diferentes áreas e temas. No caso de Polaridades, por exemplo, em que as fotografias da lua tiradas pela NASA são apropriadas, o uso de uma imagem que é um produto e reflexo de uma corrida espacial e disputa geopolítica não só diz respeito à revolução tecnológica daquele tempo, mas pode também ser lido em ótica similar a de Circumambulatio, em que Geiger e o grupo refletem sobre heranças arcaicas ligadas a formas circulares. Assim, a lua, que frequentemente aparece como elemento simbólico central em diversas culturas e rituais humanos, tanto pode ser vista pela ótica de um símbolo primordial e totalizante, quanto pela simbologia de disputas geopolíticas modernas que determinam interpretações de forças duais e opostas em suas narrativas. Ou, ainda, pode servir como metáfora para um território neutro, já que permanece fora do domínio das divisões geopolíticas da terra. Logo, Polaridades abre-se para diversos significados, através de possíveis conexões indicadas na superfície ou exterioridade de suas imagens.

No mais, além de quebrar com a divisão entre linguagens de meios diferentes, o trabalho de Geiger também começou a tocar na questão da distribuição de imagens, que seria chave na formação de um imaginário contemporâneo. Como Flusser argumentou, o significado das fotografias não se dá somente em sua codificação interna, mas, e sobretudo, em seus canais de distribuição (2002: 49). Assim, a distribuição e circulação de fotografias seriam conectadas ao que ele chama de extensões do aparelho fotográfico. De acordo com 0 filósofo, o aparelho, que é parte do universo fotográfico, não tem uma área definivel, e, logo, os canais de distribuição de imagens fotográficas seriam parte fundamental na definição do significado e função dessas imagens. Flusser observa contudo que esses processos de distribuição não são constantes, e usa um exemplo muito próximo à incursão de Geiger pela distribuição de imagens fotográficas em Polaridades:

Canais dispõem de dispositivos que permitem a determinadas fotografias deslizarem de um canal para o outro. Fotografias do homem na Lua podem transitar entre revista de astronomia e parede de consulado americano, daí para exposição artística, e daí para álbum de ginasiano. A cada vez que troca 
de canal, a fotografia muda de significado: de científica passa a ser política, artística, privada. A divisão das fotografias em canais de distribuição não é operação meramente mecânica: trata-se de operação de transcodificação. (Flusser, 2002: 50).

Assim, pode-se analisar que Geiger intersectou e mudou os canais de distribuição de uma imagem emblemática - da lua durante a corrida espacial -, a qual ela retirou de um importante canal de distribuição - aquele que John Berger apontou como sendo a primeira revista dentro dos meio de comunicação de massa, a Life ${ }^{12}$, iniciada em 1936 (2009: 53). Portanto, desviando essa imagem da codificação dada por seu representativo canal de distribuição original - isto é, de um território conquistado pelos Estados Unidos física e simbolicamente - Geiger também subverte o significado da imagem, problematizando sua narrativa e destacando sua propensão para ambiguidade simbólica, abrindo-a, assim, para novas codificações.

Se Circumambulatio já anunciava uma expansão da prática de Geiger em direção a novas mídias, em Polaridades a inserção de imagens da mídia de massa (fotografia) em um meio que até então era usado por Geiger de acordo com certas diretrizes específicas de linguagem (gravura) marcou a partida de sua prática em direção a um contexto exterior à linguagem específica com que lidava até então. Sobre a confluência dos meios de fotografia e gravura em Polaridades, e a abertura dessa série a significados exteriores ao campo da arte, Geiger analisa:

Considero indivisível a série Polaridades de fotogravuras em metal e serigrafia (1970-74), não como 'categoria', mas por trazer à tona o conceito de ideia como pressuposto indissociável, tanto pelo significado fotográfico das imagens (os primeiros registros do solo lunar transmitidos pela NASA), transformadas através de processo gráfico experimental, quanto pelo de sua veracidade de informação. Isso se completa na dualidade dos próprios títulos: Certo $x$ errado, Centro $x$ periferia, Opostos x iguais, A parte x o todo, etc [...] (Geiger, 2012)

Com essa série, Geiger levou adiante o processo de expansão e conexão de linguagens de diferentes mídias, e de investigação sobre o processo de abertura das significações de uma imagem. Assim, em um nível metafórico, tomou o território da lua como um espaço neutro fora da divisão geopolítica da Terra, de onde ela poderia criticar as políticas do seu próprio território nacional. A artista declara que usou como referência o fato de que no Hyde's Park Speakers' Corner (a "esquina dos oradores", no parque em Londres) quem sobe em um caixote pode falar e criticar livremente a monarquia regente, já que não teria os pés no chão do reinado (2014). Geiger afirma que, metaforicamente, usando uma imagem da lua ela também estava pisando fora do território nacional brasileiro e, logo, poderia ter liberdade de expressão

${ }^{12}$ Como Berger observou, o título da revista carrega a profética indicação e promessa de que suas famosas imagens são vida (2009: 54). 
sobre ele. Assim, em uma perspective poética, Geiger tomou a classificação estrita da NASA a respeito do "certo" e "errado" das imagens fotográficas da lua como símbolo do dualismo da classificação das posições políticas no país. Em uma das gravuras de série, Sem título (1974), a conexão dessa paisagem distante e árida da lua com uma realidade mais próxima e imediata é mais explicitada quando a superfície lunar é cortada na mesma forma que as bordas do território brasileiro (fig.6).

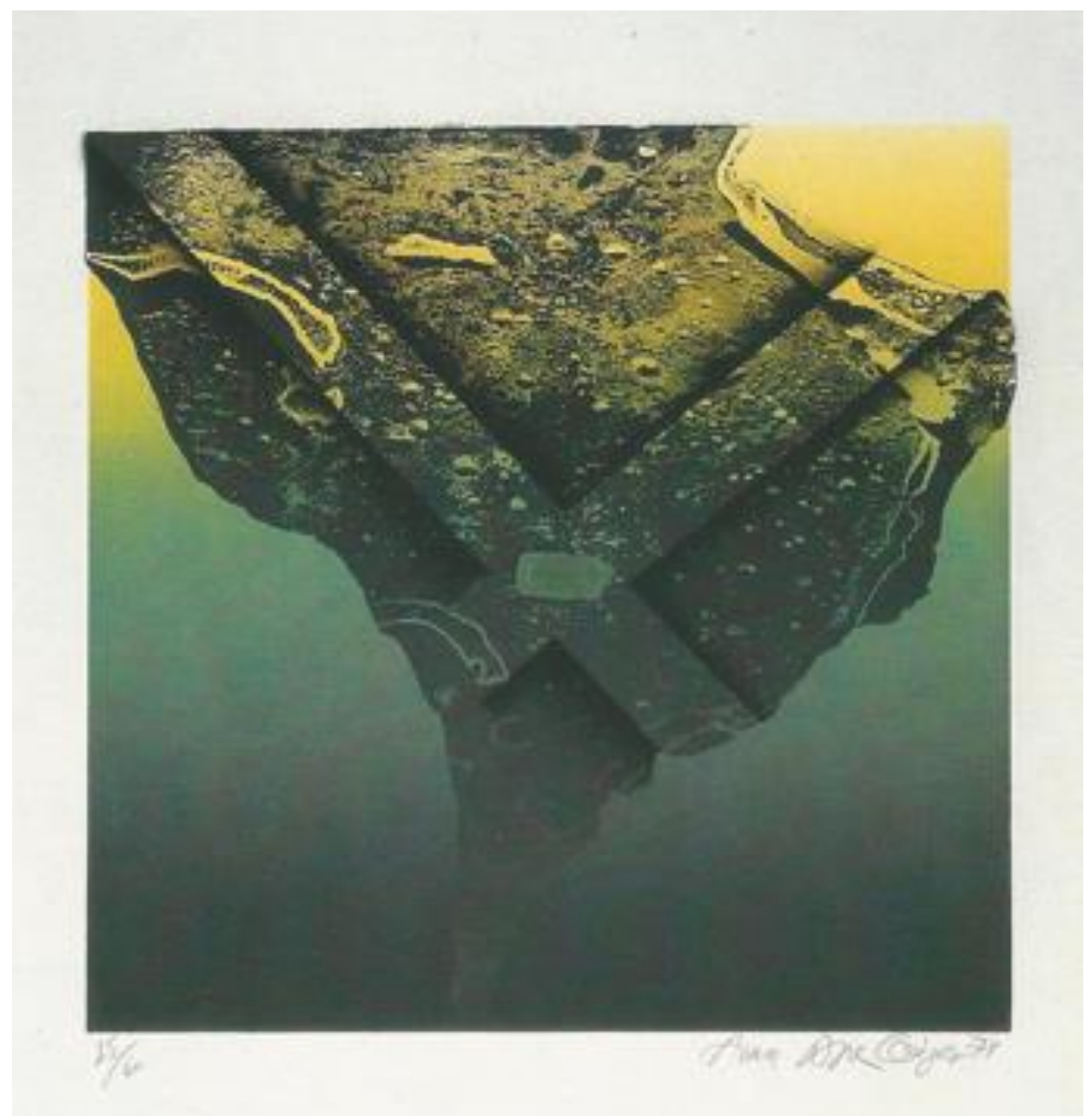

Fig. 6: Sem Título, 1974 (serigrafia e fotogravura em metal, 39 × 39,5 cm). Fonte: Geiger, 1996 : 35.

Dessa forma é possível argumentar que no trabalho de Geiger a apropriação de imagens não segue estritamente uma operação duchampiana de dar um novo significado para um material apropriado através do gesto de incorporação ao âmbito da arte ou, em outras palavras, não confere novo valor a esse material, dissociado de sua origem. Ao invés disso, o significado e função preexistentes são trazidos para o trabalho de arte como um elemento central 
de sua constituição, e um elemento de conexão entre o trabalho e o mundo lá fora. Por outro lado, esses materiais apropriados não permanecem estagnados em seu primeiro significado, mas se abrem para novas conexões feitas por operações estéticas e conceituais, como demonstrado em Polaridades. A meu ver, essa é uma operação dialética ou semântica similar à apontada por Glória Ferreira como característica da obra de artistas da geração dos anos 70 que se ligava "ao mundo material e histórico" (2009: 25). Isto é, trabalhando com jornais, produtos e imagens apropriadas, esses artistas estavam ligando suas práticas a um contexto sociopolítico que era parte da circulação cotidiana desses materiais. Essas operações, conforme Ferreira ressalta, criaram no Brazil uma "politização da arte em seus próprios termos", já que a "política das artes" era "inscrita na própria linguagem e nas modalidades de sua inserção na sociedade" (2009: 25).

Isso também leva a uma reflexão sobre o meio usado por Geiger na exterioridade de sua linguagem, isto é, a fotografia. Analisando sua obra em retrospecto, Adolfo Montejo Navas observa que fotografia é um elemento recorrente na trajetória de Geiger, que depois de Polaridades foi frequentemente usada pela artista como forma de desafiar questões em torno da construção de narrativas sociais e visibilidades (2009). Usando imagens fotográficas apropriadas de meios de circulação de massa, a artista traça conexões de seu tempo com a construção da história e memória, e de como imagens tornaram-se elementos ativos nessas narrativas e na construção de entendimentos da "realidade".

No que diz respeito ao papel específico das imagens fotográficas como lugar para mutações e conexões, Navas observa que, nas múltiplas poéticas de Geiger, o elemento fotográfico não é uniforme nem tampouco o meio para um fim, mas, tendo uma função "contagiosa" e "metafórica", "se transforma em diferentes registros e suportes" (2009: 3). Assim sendo, os significados dessas imagens e seus usos tendem a transitar para fora delas. Esse potencial conector de imagens também sugere uma relação dialética entre a função, 0 significado, a natureza, e os meios pelos quais as fotografias transitam. Em Polaridades, a mutação entre os significados e a materialidade das fotografias é exemplificado no processo de passagem das imagens da lua, providas pela NASA, para outros meios, como a gravura. Como já analisado, seus significados, que eram ligados ao fato de serem fotografias da revista Life, adulteram-se, já que eles se tornam outra coisa quando transportados ao meio da gravura. Navas destaca que a formação de Geiger como gravadora dá à ela uma base de análise do "trânsito da aura na reprodutibilidade", que é possível de ser explorado no meio fotográfico (2009: 5).

Navas também observa que a equação da fotografia em apresentar um "aqui e outrora", isto é, de trazer um "aqui" e um "além" de outro tempo e espaço, é 
de especial interesse para Geiger (2009: 5) - e, eu argumentaria, é onde ela interliga seus interesses e preocupações que transitam entre memórias arcaicas e históricas, passadas e presentes. Como Navas aponta, essa equação de síntese e transporte da fotografia "permite-lhe revisitar com outro olhar coisas 'sem tempo', na história da arte e da cultura, tomando iconografias diversas como sendo arqueologias contemporâneas" (2009: 5). Esse constitutivo "conflito espaço-temporal" está presente em trabalhos de Geiger como Circumambulatio e Polaridades, evidenciando o papel da fotografia e sua abertura a uma exterioridade ao interconectar o arcaico e contemporâneo, primitivo e moderno, particular e todo.

Logo, pode-se concluir que a questão da mutação e contaminação de meios e linguagens e o papel central da fotografia nessas operações não são desconectados da pesquisa de Geiger sobre o trânsito anacrônico de imagens e símbolos por diferentes tempos e culturas. Assim sendo, Certo-Errado e Aqui é o Centro, da série Polaridades, partem de um território específico codificado em imagens - da superfície lunar - para guiar a representação desse território em diversas camadas de significados que se relacionam a questões passadas e presentes, históricas e atemporais, privadas e de um contexto socio-cultural que interessavam a Geiger na época. Em um nível simbólico, a relação imediata com a questão do centro como símbolo arcaico torna-se evidente. Tendo começado uma pesquisa sobre a representação simbólica no trabalho feito diretamente no solo e com imagens em sua maioria apropriadas de culturas e lugares do passado em Circumambulatio, Geiger partiu agora da transferência dessas representações anciãs e mitológicas de um centro para a tecnológica corrida espacial que buscava alcançar um centro vazio no espaço, isto é, a lua.

Como já indicado, essa problemática de certas formas elementares reaparecendo e sendo resignificadas em um eterno retorno ganha uma dimensão sem precedente com o avanço da tecnologia que criou um ciclo de reprodução e circulação de uma cultura visual. A imagem de centro e círculo, que foi primeiramente explorada em Circumambulatio, reaparece em Polaridades na forma da lua como um objeto de desejo dos anos 1960, que é por sua vez um retorno: não muito diferente do astro reverenciado em rituais pagãos, a humanidade, com a corrida espacial, recoloca novamente a lua no centro de sua cultura simbólica de poder. Uma das formas circulares mais veneradas em várias civilizações, a lua representa uma qualidade reflexiva e mutante de tal forma. Não produzindo luz por si só, depende da luz do sol para refletir e espelhar sua forma a ser vista pelos humanos. Sendo capturada em fotografias nessa lógica de uma projeção através de luz alheia, a lua, em suas interpretações simbólicas, parece reproduzir ad infinitum a lógica de uma superfície suscetível a novas projeções. Geiger busca estender o mecanismo de captura de uma realidade que se manifesta através de projeções e usa 0 
potencial reflexivo dessa imagem da superfície da lua para projetar uma série de proposições que cruzam sua própria temporalidade - às vezes de forma anacrônica - e se conectam a questões do contexto social, político e cultural de seu tempo.

Essa relação temporal e anacrônica indicada no trabalho de Geiger relacionase à definição do filósofo Giorgio Agamben sobre o que é ser contemporâneo. Agamben argumenta que os "verdadeiramente contemporâneos" são aqueles que se relacionam com o seu tempo através de deslocamentos, desconexões e anacronismos (2009: 58). Partindo da noção de Nietzsche sobre uma relação intemporal com o presente como forma de se posicionar em relação a ele, Agamben leva o argumento adiante afirmando que ter uma experiência conflituosa e disjunta com o presente é a única forma de não se cegar por suas luzes. Como o autor afirma "aqueles que coincidem muito plenamente com a época, que em todos os aspectos a esta aderem perfeitamente, não são contemporâneos porque, exatamente por isso, não conseguem vê-la, não podem manter fixo o olhar sobre ela" (2009: 59).

No mais, ser capaz de ver e articular criticamente as disjunções do presente não significa que o "verdadeiramente contemporâneo" viva uma relação nostálgica com outros tempos, mas sim que tenha "singular relação com 0 próprio tempo", simultaneamente aderindo e mantendo uma distância dele e, nessa relação singular, pode-se ver o passado inscrito no presente (Agamben, 2009: 59). Como Agamben argumenta, "a contemporaneidade se escreve no presente assinalando-o antes de tudo como arcaico" (2009: 69). Agamben também observa uma relação desse arcaico com arkhé, o sentido grego de "começo" ou "origem" que se desenvolve igualmente em arquivo. Mas essa "origem" não seria achada em um passado cronológico ou história linear, mas transitaria através de um "tornar histórico" onde a relação do contemporâneo com o passado e história não cessaria de ser viva e em fluxo. Nesse sentido, o arcaico e o passado são sempre distantes e próximos do presente, em um constante fluxo que, potencialmente, pode ser apreendido pelo verdadeiro contemporâneo.

Em afinidade com o pensamento de Agamben, Geiger parece ser capaz de ver os aspectos arcaicos de seu presente. Identificando traços dessas disjunções em um dos elementos principais que moldam o que constitui o presente desde a segunda metade do século XX, isto é, imagens reprodutíveis, Geiger usa esses lugares de fratura do contemporâneo para desenvolver uma experiência coletiva do presente sugerida por imagens. Não só apropriando-se de imagens, mas também recriando e interferindo parodicamente em algumas delas, Geiger interessa-se em investigar como esses traços do arcaico e suas fraturas são ao mesmo tempo levadas adiante e transformadas quando 
transferidas de imagem em imagem, de um meio para o outro - como é o caso de Polaridades.

Com bases nessas análises, pode-se concluir que desde suas primeiras apropriações de fotografias que circulavam na mídia de massa, Geiger criou estratégias para conectar elementos gráficos da gravura com o grafismo da nova cultura da imagem, além de estabelecer conexões conceituais com os crescentes canais de circulação dessas imagens e informações. Com isso, argumenta-se, ela estabeleceu uma operação crítica com os novos modelos e aparatos de inscrição de uma memória cultural, social e histórica. Além de estar participando da formação do presente através do alcance e distribuição da informação, esses novos mecanismos da mídia de massa e sua cultura da imagem começavam a afetar não só a formação do presente, mas moldar uma nova relação com a memória - em que o volume e velocidade do que se "lembra" e se "esquece" cresce vertiginosamente. Com os ciclos de retorno dessas imagens, pode-se concluir que essas novas formas de inscrições também participam de uma projeção do futuro.

Assim, criando estratégias de apropriação de materiais e sistemas, que no futuro tornaria-se-iam uma recorrente metodologia na virada arquivística ocorrida nas artes pode-se analisar que essa fase do trabalho de Geiger abre precedentes para uma importante reatualização das conexões entre memória, arquivo e a sociedade imagética e midiática. Incorporando imagens através de novas tecnologias de reprodução, Geiger desenvolveu estruturas e metodologias em seus trabalhos que criticamente lidavam com o "estoque" imagético do presente e a participação deste na formação de um cenário cultural e da memória. Logo, as narrativas de trabalhos como Circumambulatio e Polaridades lidavam também com a fragmentação imagética das narrativas do presente. Nesse sentido, eles podem ser vistos como um marco que antecipa a virada arquivística que começaria a lidar mais sistematicamente com uma interpretação crítica do papel do arquivo no armazenamento de elementos, imagens e objetos do passado na formação de narrativa vigentes no presente - um retorno ao arquivo e à memória que, como argumentado por outros autores, responde também à fragmentação das narrativas a partir da segunda metade do século XX (Huyssen 2000, Lev Manovich 2001, Van Alphen, 2014).

Se, como analisado por Ernst van Alphen, a virada aos arquivos é uma reação à queda das narrativas lineares e conclusivas - um papel que antes das narrativa progressistas e cientificas desde o lluminismo era desempenhado por historias míticas e religiosas (2014: 7), o aspecto arquivístico de Circumambulatio e Polaridades de fato conecta a prévia experiência existencial do mundo através de narrativas míticas e ao que van Alphen descreve como a performatividade das narrativas pós-lineares do arquivo (2014: 9). De acordo 
com van Alphen, essas narrativas do arquivo funcionariam performativamente porque elas não seriam mais capazes ou não estariam mais tentando legitimar um valor conclusivo ou verdade. Relacionando-se a essa lógica, pode-se dizer que essa fase do trabalho de Geiger lida com diferentes materiais, metodologias e fontes da cultura ao seu redor como elementos a serem criticamente incorporados na sua prática para criar proposições e narrativas investigavas e abertas a novas interpretações. Assim, essas obras criam arquivos incidentais que redistribuem imagens e conectam-nas a anacronismos e diferentes interpretações que cruzam uma visão de mundo privada com um imaginário coletivo e logo, também, com a memória coletiva.

\section{Referências}

AGAMBEN, Giorgio. O que é o contemporâneo e outros ensaios. Chapecó: Argos, 2009.

van ALPHEN, Ernst. Staging the Archive: Art and Photography in the Age of New Media. London: Reaktion Books, 2014.

ALVES, Camila G., PINTO, Henrique G. 'A trajetória intelectual de Pedro Pinchas Geiger segundo suas obras na Revista Brasileira de Geografia'. III Encontro Nacional de História do Pensamento Geográfico I Encontro Nacional de Geografia Histórica, 2012, Rio de Janeiro. História da Geografia no Brasil, 2012.

ALLOWAY, Lawrence. American Pop art. Nova lorque: Mcmillan Publishing, 1974.

BENJAMIN, Walter. Passagens. Belo Horizonte: Editora UFMG, 2006.

BERGER, John. About Looking. London: Bloomsbury Publishing, 2009.

BERGSON, Henri. Matéria e memória: ensaio sobre a relação do corpo com o espirito. 2 ed. São Paulo: Martins Fontes, 1999.

BROCKMEIER, Jens. 'Remembering and Forgetting: Narrative as Cultural Memory'. In: Culture and Psychology, 8/1 pp.5-14, 2002.

BROCKMEIER, Jens. Beyond the Archive: memory, narrative, and the autobiographical process. Oxford: Oxford University Press, 2015.

COSTA, Luiz C. A gravidade da imagem: arte e memória na contemporaneidade. Rio de Janeiro: Faperj, Quartet, 2014.

DIDI-HUBERMAN, Georges. L'empreinte. Paris: Centre Georges Pompidou, 1997.

ELIADE, Mircea. Imagens e Símbolos: Ensaios sobre o simbolismo mágico-religioso. São Paulo: Martins Fontes, 1991.

FERREIRA, Glória. Arte como questão: Anos 70. Catálogo. São Paulo: Instituto Tomie Ohtake, 2009.

FLUSSER, Vilém. Towards a Philosophy of Photography. London: Reaktion Books, 2000.

FLUSSER, Vilém. Filosofia da Caixa Preta: ensaios para uma futura filosofia da fotografia. Rio de Janeiro: Relume Dumará, 2002. 
GEIGER, Anna B. Anna Bella Geiger: Constelações. Catálogo. Rio de Janeiro: MAM. [catálogo exposição, 1996.

GEIGER, Anna B. Anna Bella Geiger: Circa MMXI. São Paulo: Centro Cultural dos Correios, 2012. [catálogo exposição, disponível em: <http://www.circa2011.com.br/aexposicao>, visitado em 14/07/2015].

GEIGER, Anna B. Anna Bella Geiger: entrevista [17/01/2014]. Entrevistador: Fernanda Albertoni. Rio de Janeiro, 2014.

HUYSSEN, Andreas. Seduzidos pela memória: arquitetura, monumentos e mídia. Rio de Janeiro: Aeroplano, 2000.

JAREMTCHUK, Dária Anna Bella Geiger: Passagens Conceituais. São Paulo, Belo Horizonte: C/Arte, FAPESP, 2007.

MANOVICH, Lev. The Language of New Media. Cambridge, Mass: The MIT Press, 2001.

NAVAS, Adolfo M. (org.) Anna Bella Geiger: Territórios, Passagens, Situações. Catálogo. Rio de Janeiro: Casa da Palavra, 2007.

NAVAS, Adolfo M. (org.) Anna Bella Geiger: fotografia alem da fotografia. 1972-2008. Catálogo. São Paulo: Caixa Cultural, 2009. 